\title{
Pemetaan dan Pengelompokan Isyarat Akustik Alat Muzik Tradisional Melayu Menggunakan Kaedah Analisis Isyarat Statistik
}

\author{
(Mapping and Clustering of the Acoustic Signal of Malay Traditional Musical Instruments using Statistical Analysis \\ Method)
}

Abdul Rahim Bahari, Mohd Zaki Nuawi, Ab Samad Kechot, Firdaus Mohd Hamzah \& Suziana Mat Saad*

ABSTRAK

\begin{abstract}
Kertas kerja ini membincangkan tentang kajian pembangunan kaedah pemetaan dan pengelompokan isyarat akustik alat muzik tradisional Melayu. Isyarat akustik bagi knot B3 direkod menggunakan sistem perekodan bunyi yang direkabentuk berasaskan gabungan mikrofon, modul kuasa dan sistem pemerolehan data. Alat muzik tradisional Melayu yang terlibat adalah cak lempong, seruling dan gambus. Rakaman dalam domain masa menunjukkan bentuk gelombang yang pelbagai mengikut kaedah alat tersebut dimainkan. Tahap persamaan antara dua isyarat akustik yang berbeza bagi alat muzik tradisional Melayu yang sama ditentukan melalui ujian ANOVA. Sehubungan dengan itu, bagi menjayakan proses pemetaan dan pengelompokan, kaedah analisis isyarat statistik alternatif iaitu Integrated Kurtosis-based Algorithm for Z-notch filter (I-kazTM) dan Mesokurtosis Zonal Nonparametric (M-Z-N) digunapakai bagi mengekstrak ciri-ciri yang terdapat dalam isyarat tersebut. Pengenalpastian dilakukan menggunakan kombinasi pekali I-kaz dan pekali M-Z-N. Hasil kajian menunjukkan keputusan pencirian isyarat akustik melalui pemetaan dan pengelompokan telah berjaya dilaksanakan melalui kaedah yang dibangunkan ini.
\end{abstract}

Kata kunci: Pemetaan dan pengelompokan; I-kazTM; M-Z-N; alat muzik tradisional Melayu

\section{ABSTRACT}

This paper discusses the development of a method for mapping and clustering acoustic signal of traditional Malay musical instruments. The acoustic signal for knot B3 has been recorded using a sound recording system which has been designed based on the combination of a microphone, a power module and a data acquisition system. The Malay traditional musical instruments involved are cak lempong, flute and gambus. The recording in the time domain shows a variety of waveforms according to the instrument's method of play. The level of similarity between two different acoustic signals of same traditional Malay musical instrument has been determined by ANOVA analysis. For the mapping and clustering process, alternative methods of statistical signal analysis known as Integrated Kurtosis-based Algorithm for Z-notch Filter (I-kaz $\left.{ }^{\mathrm{TM}}\right)$ and Mesokurtosis Zonal Nonparametric (M-Z-N) has been applied to extract the signal's features. Identification is done using a combination of I-kaz and M-Z-N coefficients. The result shows that the characterization of acoustic signals of traditional Malay musical instruments through mapping and clustering has been successfully implemented by this developed method.

Keywords: Mapping and clustering; I-kaz ${ }^{\mathrm{TM}}$; M-Z-N; Malay traditional musical instruments

\section{PENGENALAN}

Alat muzik tradisional Melayu merupakan alat teknologi dan kebudayaan yang berperanan sebagai saluran komunikasi dan hiburan dengan cara mengiringi seni persembahan dalam masyarakat melalui penghasilan alunan bunyi yang pelbagai. Alat ini wujud hasil daripada kebijaksanaan masyarakat Melayu mengadaptasi alam sekitar mereka dengan keperluan hidup. Antara alat teknologi seni persembahan Melayu adalah seperti rebab, gambus, gamelan, serunai, gendang, rebana, cak lempong dan gong.
Alat muzik ini boleh diklasifikasikan kepada empat kumpulan (Nasaruddin 1989). Pertama, aerofon, menghasilkan bunyi melalui udara yang bergetar contohnya serunai, seruling, bambu, bangsi dan nafiri. Kedua, membranofon, menghasilkan bunyi melalui membran (kulit) yang bergetar contohnya gendang, rebana, jidur dan kompang. Ketiga, idionofon, menghasilkan bunyi melalui getaran badan seperti gong, kesi canang dan alat -alat gamelan. Keempat, kordofon, menghasilkan bunyi melalui tali yang bergetar seperti rebab, gambus dan kecapi. 
Asas kepada sesuatu muzik ialah penyusunan nadanada yang terhasil samaada daripada alat muzik atau peti suara seorang penyanyi. Nada-nada yang terhasil merupakan isyarat bunyi yang memiliki sifat-sifat fizikal seperti keamatan bunyi dan frekuensi bunyi. Menurut Bartholomiew (1942), tiga perkara yang diperlukan untuk alat muzik menghasilkan isyarat bunyi ialah alat yang bergetar, medium untuk memindahkan getaran dan alat penerima.

Objektif utama kajian ini adalah untuk membangunkan satu kaedah pemetaan dan pengelompokan isyarat akustik yang terhasil daripada alat muzik tradisional Melayu yang berbeza. Kertas kerja ini disusun seperti berikut. Pertama, pembangunan rekabentuk eksperimen untuk menjalankan proses merekod isyarat akustik dibentangkan. Kemudian, latar belakang teori tentang kaedah analisis isyarat statistik alternatif yang dikenali sebagai Integrated Kurtosis-based Algorithm for Z-notch filter (I-kaz ${ }^{\mathrm{TM}}$ ) dan Mesokurtosis Zonal Nonparametric (M-Z-N) dijelaskan. Seterusnya, keputusan yang diperoleh secara langsung melalui proses merekod isyarat akustik tersebut dibentangkan. Akhirnya, perbincangan mengenai pemetaan dan pengelompokan isyarat akustik dan proses pencirian kepada zon-zon tertentu secara terperinci dibentangkan.

\section{KAEDAH KAJIAN}

Kajian ini melibatkan tiga jenis alat muzik tradisional yang berbeza iaitu cak lempong, seruling dan gambus. Setiap alat muzik tradisional Melayu tersebut dimainkan oleh pakar dari pihak Akademi Seni Budaya Dan Warisan Kebangsaan (ASWARA) dan berdasarkan knot yang telah ditetapkan. Ujikaji dijalankan di dalam bilik rakaman. Setiap knot dimainkan sebanyak dua kali.

Proses merekod isyarat akustik bagi tiga jenis alat muzik tradisional tersebut adalah menggunakan rekabentuk eksperimen yang telah dibangunkan yang terdiri daripada mikrofon, modul kuasa dan sistem alat pemerolehan data seperti yang digambarkan pada Rajah 1.

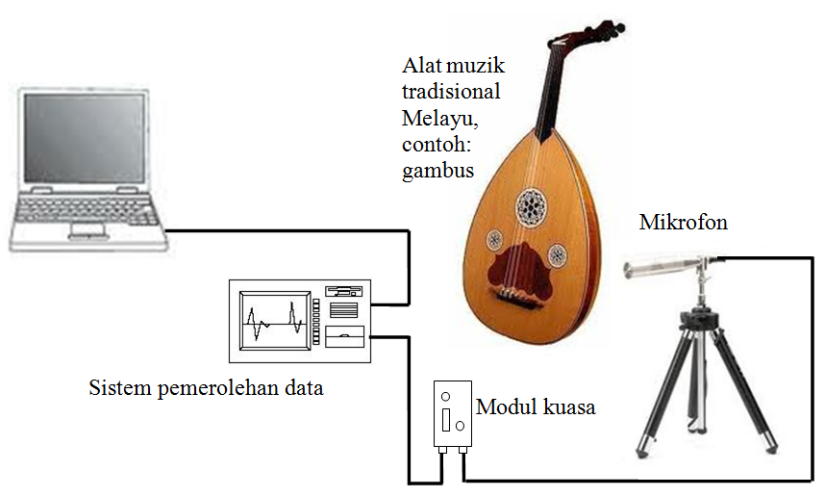

RAJAH 1. Rekabentuk skematik eksperimen
Pemilihan dan penganalisaan isyarat akustik

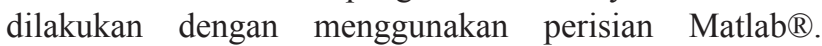
Proses penurasan dilakukan pada isyarat akustik asal yang telah dipilih bagi menuras kandungan hingar serta mendapatkan isyarat akustik bersih. Penganalisaan isyarat akustik bersih melibatkan pengaplikasian dua kaedah analisis statistik alternatif iaitu Integrated Kurtosis-based Algorithm for Z-notch filter (I-kaz ${ }^{\mathrm{TM}}$ ) dan Mesokurtosis Zonal Nonparametric (M-Z-N). Kaedah analisis I-kaz ${ }^{\mathrm{TM}}$ merupakan suatu pendekatan analisis statistik alternatif yang telah diperkenalkan oleh Nuawi et al. (2008). Analisis I-kaz digunakan dalam kajian ini kerana kaedah ini adalah sangat baik dalam mengesan perubahan amplitud dan frekuensi yang berlaku dalam sesebuah isyarat.

Pembangunan kaedah analisis statistik I-kaz ${ }^{\mathrm{TM}}$ adalah berdasarkan konsep penyerakan data terhadap suatu nilai pusat serakan yang dipanggil sentroid. Pekali I-kaz, Z $\infty$ ditakrifkan pada Persamaan 1.

$$
Z^{\infty}=\frac{1}{n} \sqrt{K_{L} S D_{L}^{4}+K_{H} S D_{H}^{4}+K_{V} S D_{V}^{4}}
$$

yang mana $K_{\mathrm{L}}, K_{\mathrm{H}}$ dan $K_{\mathrm{V}}$ adalah nilai kurtosis bagi julat frekuensi rendah (L), julat frekuensi tinggi (H) dan julat frekuensi sangat tinggi (V). $S D_{\mathrm{L}}, S D_{\mathrm{H}}$ dan $S D_{\mathrm{V}}$ pula merupakan nilai sisihan piawai bagi julat frekuensi rendah, julat frekuensi tinggi dan julat frekuensi sangat tinggi.

Kurtosis, $K$ adalah momen statistik peringkat ke-empat iatu statistik isyarat global yang sangat sensitif terhadap pepaku bagi sesuatu data. Nilai kurtosis dinyatakan dalam Persamaan 2.

$$
K=\frac{1}{n \sigma^{4}} \sum_{i=1}^{n}\left(x_{i}-\mu\right)^{4}
$$

yang mana $\sigma$ adalah varians bagi set data tersebut. Untuk taburan Gaussian, nilai kurtosis adalah sekitar 3.0. Nilai kurtosis yang tinggi menunjukkan terdapat nilai yang terlalu tinggi berbanding nilai yang sepatutnya berada dalam taburan Gaussian. Kurtosis digunakan dalam bidang kejuruteraan untuk pengesanan simptomsimptom kerosakan kerana sifatnya yang sensitif terhadap kewujudan amplitud tinggi (Qu \& He 1986). Sisihan piawai pula mengukur sisihan taburan data terhadap nilai min, $\mu$. Sisihan piawai dinyatakan seperti dalam Persamaan 3.

$$
s=\left(\frac{1}{n} \sum_{i=1}^{n}\left(x_{i}-\mu\right)^{2}\right)^{\frac{1}{2}}
$$


Kaedah Mesokurtosis Zonal Nonparametric (M-Z-N) pula merupakan pendekatan kaedah penganalisaan isyarat alternatif yang dikembangkan berdasarkan kepada kaedah I-kaz ${ }^{\mathrm{TM}}$. Kaedah ini dibangunkan berdasarkan konsep penyerakan data terhadap nilai punca min kuasa dua (p.m.k.d) pada taburan data tersebut (Nuawi et al. 2012). Nilai pekali M-Z-N dikira berdasarkan Persamaan 4.

$$
M-Z-N=\frac{1}{M} \sum_{j=1}^{M}\left[\frac{1}{N} \sum_{i=1}^{N}\left(x_{i}-p \cdot m \cdot k \cdot d\right)^{2}\right]
$$

dengan $M$ adalah bilangan segmen dan $N$ adalah bilangan data di dalam segmen.

Keputusan analisis statistik yang diperoleh melibatkan pekali I-kaz dan pekali M-Z-N. Nilai-nilai ini akan digunakan sebagai sumber untuk menjalankan proses pemetaan dan pengelompokan berdasarkan knot yang dipilih bagi membezakan isyarat akustik setiap alat muzik tersebut. Carta alir bagi proses pemetaan dan pengelompokan isyarat akustik alat muzik tradisional Melayu adalah seperti yang dipaparkan pada Rajah 2.

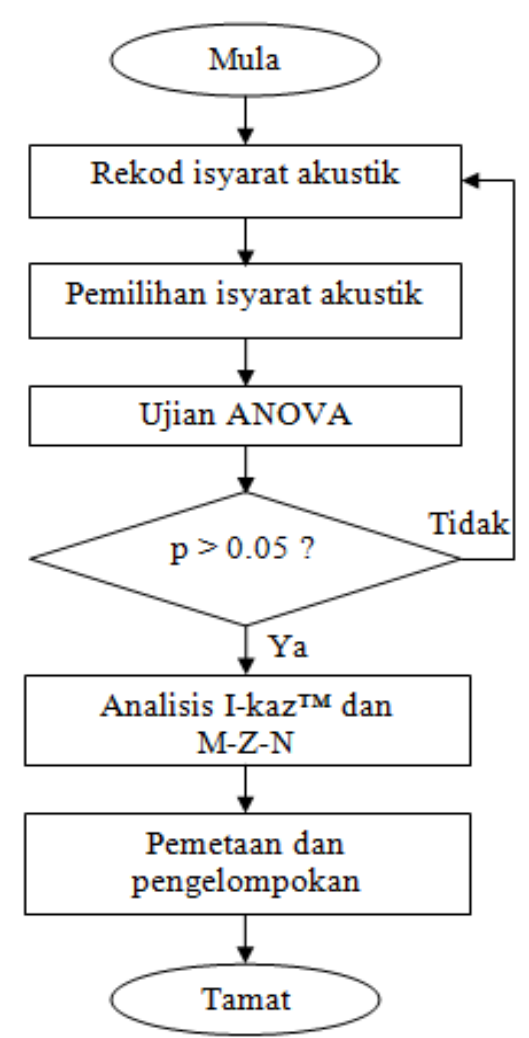

RAJAH 2. Carta alir bagi kajian pemetaan dan pengelompokan isyarat akustik alat muzik tradisional Melayu

\section{HASIL DAN PERBINCANGAN}

Rajah 3 mempersembahkan domain masa isyarat akustik knot B3 bagi alat muzik cak lempong, seruling dan gambus. Bentuk gelombang isyarat akustik yang telah direkod adalah berbeza mengikut cara permainan alat muzik tersebut. Dapat diperhatikan bahawa domain masa isyarat akustik cak lempong adalah teredam. Apabila cak lempong diketuk sebanyak sekali pada knot B3, isyarat akustik akan terjana dengan sangat pantas. Setelah amplitud maksimum dicapai melalui getaran maksimum cak lempong tersebut, isyarat akustik akan mula menyusut secara eksponen disebabkan redaman getaran cak lempong. Bagi alat seruling pula, domain masa isyarat akustik meningkat secara pantas apabila ditiup. Gelombang tekanan isyarat akustik akan terjana sepanjang masa seruling ditiup dan akan mula menyusut apabila tiupan diberhentikan. Seterusnya, bentuk gelombang domain masa isyarat akustik gambus juga adalah teredam, sama seperti bentuk gelombang cak lempong. Ini adalah disebabkan getaran tali gambus akan meningkat ke tahap getaran maksimum apabila tali gambus dipetik sebanyak sekali pada knot B3. Isyarat akustik akan mula menyusut apabila getaran maksimum dicapai mengakibatkan bentuk isyarat domain masa menyusut secara eksponen.
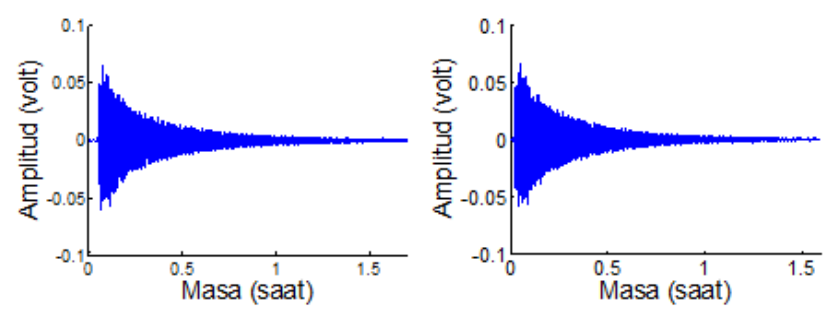

(a)
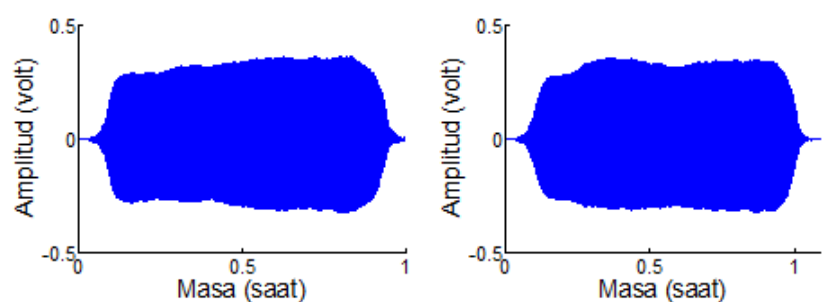

(b)
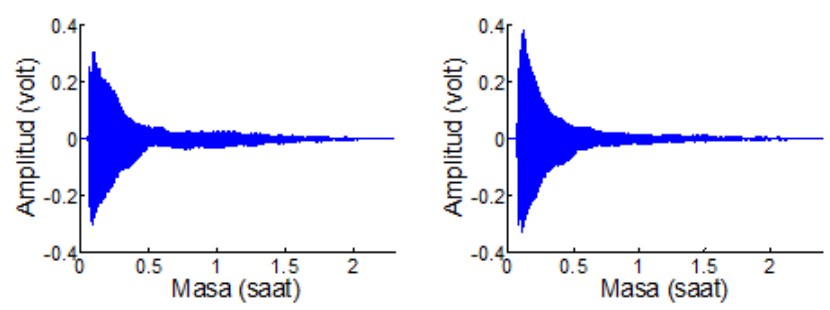

(c)

RAJAH 3. Domain masa isyarat akustik knot B3 (a) cak lempong (b) seruling (c) gambus

\section{ANALISIS ANOVA}

Proses merekod isyarat akustik adalah sebanyak dua kali, bertujuan bagi membuktikan bahawa isyarat akustik yang direkod daripada sesebuah alat muzik tradisional adalah tepat dan seragam. Analisis ANOVA dilakukan untuk menentukan tahap kepersisan antara kedua- 
dua isyarat tersebut. Tahap kepersisan adalah penting bagi membuktikan bahawa setiap isyarat yang direkod mempunyai persamaan yang tinggi. Jadual 1 menunjukkan nilai $\mathrm{p}$ bagi setiap alat muzik.

JADUAL 1. Nilai p alat muzik tradisional

\begin{tabular}{ll}
\hline Alat Muzik & Nilai p \\
\hline Cak Lempong & 0.834 \\
Seruling & 0.732 \\
Gambus & 0.795 \\
\hline
\end{tabular}

Berdasarkan jadual tersebut, nilai p bagi ketiga-tiga alat adalah melebihi 0.05 . Ini membuktikan bahawa keduadua isyarat akustik bagi alat muzik tertentu mempunyai ciriciri kepersisan yang tinggi. Oleh yang demikian, analisis lanjutan boleh dilakukan pada isyarat yang mempunyai kepersisan yang tinggi. Ini adalah disebabkan kaedah pemetaan dan pengelompokan yang akan digunakan dalam kajian ini memerlukan sumber data yang persis dan tepat. Contoh boxplot isyarat akustik bagi alat cak lempong dan gambus ditunjukkan pada Rajah 4.

\section{ANALISIS STATISTIK}

Secara umumnya, tahap perbezaan isyarat akustik antara setiap alat muzik yang terlibat dalam kajian ini tidak dapat dikenalpasti dengan jelas berdasarkan kepada keputusan yang dipersembahkan pada Rajah 3. Proses pemetaan dan pengelompokan isyarat akustik tidak dapat dilaksanakan menggunakan sumber data berasaskan isyarat domain masa tersebut. Dengan itu, kaedah analisis statistik digunakan bagi membantu proses pengenalpastian tahap perbezaan isyarat akustik dapat dilakukan dengan tepat. Kaedah pengekstrakan statistik ini adalah berdasarkan dua parameter statistik yang telah dipilih iaitu pekali I-kaz dan pekali M-Z-N.

Dalam analisis I-kaz ${ }^{\mathrm{TM}}$, domain masa isyarat akustik dituras kepada tiga julat frekuensi yang berbeza iaitu 0 -

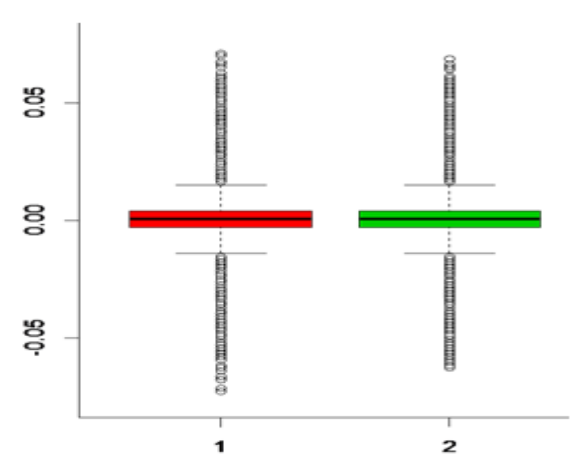

(a)

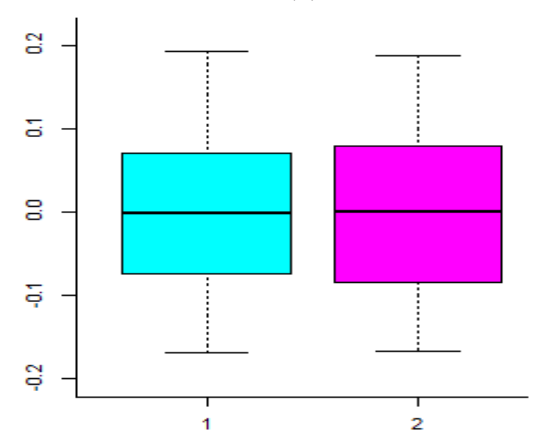

(b)

RAJAH 4. Boxplot bagi knot B3 (a) cak lempong (b) seruling

$5 \mathrm{kHz}$ (julat frekuensi rendah), 5 - $10 \mathrm{kHz}$ (julat frekuensi tinggi) dan $10-20 \mathrm{kHz}$ (julat frekuensi sangat tinggi). Parameter kurtosis bagi setiap julat frekuensi yang telah dinyatakan iaitu $K_{\mathrm{L}}$ (kurtosis bagi julat frekuensi rendah), $K_{\mathrm{H}}$ (kurtosis bagi julat frekuensi tinggi) dan $K_{\mathrm{V}}$ (kurtosis bagi julat frekuensi sangat tinggi) serta parameter sisihan piawai iaitu $S D_{\mathrm{L}}$ (sisihan piawai bagi julat frekuensi rendah), $S D_{\mathrm{H}}$ (sisihan piawai bagi julat frekuensi tinggi) dan $S D_{\mathrm{v}}$ (sisihan piawai bagi julat frekuensi sangat tinggi) dikira menggunakan Persamaan 2 dan Persamaan 3. Proses pengiraan tersebut dilaksanakan menggunakan perisian Matlab ${ }^{\circledR}$ dan nilai parameter tersebut ditunjukkan pada Jadual 2. Melalui nilai kurtosis dan sisihan piawai, nilai pekali I-kaz dihitung menggunakan Persamaan 1 dan

JADUAL 2. Kurtosis dan sisihan piawai bagi setiap julat frekuensi dan alat muzik

\begin{tabular}{ccccc}
\hline Isyarat & Parameter & Cak lempong & Seruling & Gambus \\
\hline & $K_{\mathrm{L}}$ & 10.565 & 1.892 & 16.135 \\
& $K_{\mathrm{H}}$ & 18.018 & 3.434 & 952.977 \\
1 & $K_{\mathrm{V}}$ & 3.197 & 4.792 & 1675.898 \\
& $S D_{\mathrm{L}}$ & $8.469 \times 10^{-3}$ & $1.843 \times 10^{-1}$ & $4.208 \times 10^{-2}$ \\
& $S D_{\mathrm{H}}$ & $7.536 \times 10^{-5}$ & $5.259 \times 10^{-4}$ & $1.494 \times 10^{-3}$ \\
& $S D \mathrm{~V}$ & $8.892 \times 10^{-5}$ & $2.399 \times 10^{-4}$ & $4.166 \times 10^{-4}$ \\
\hline & $K_{\mathrm{L}}$ & 8.871 & 1.811 & 25.623 \\
& $K_{\mathrm{H}}$ & 3.747 & 3.832 & 774.075 \\
& $K_{\mathrm{V}}$ & 2.940 & 4.173 & 1176.426 \\
& $S D_{\mathrm{L}}$ & $9.465 \times 10^{-3}$ & $1.921 \times 10^{-1}$ & $3.689 \times 10^{-2}$ \\
& $S D_{\mathrm{H}}$ & $6.835 \times 10^{-5}$ & $7.411 \times 10^{-4}$ & $9.135 \times 10^{-4}$ \\
& $S D \mathrm{~V}$ & $8.734 \times 10^{-5}$ & $2.593 \times 10^{-4}$ & $2.385 \times 10^{-4}$ \\
\hline
\end{tabular}


JADUAL 3. Keputusan analisis statistik pekali I-kaz bagi knot B3

\begin{tabular}{ccc}
\hline Alat Muzik & Isyarat 1 & Isyarat 2 \\
\hline Cak Lempong & $3.0677 \times 10^{-9}$ & $3.8119 \times 10^{-9}$ \\
Seruling & $1.0820 \times 10^{-6}$ & $1.0799 \times 10^{-6}$ \\
Gambus & $7.0086 \times 10^{-8}$ & $6.3777 \times 10^{-8}$ \\
\hline
\end{tabular}

ditunjukkan pada Jadual 3.

Bagi analisis M-Z-N pula, isyarat akustik dipecahkan kepada 5 segmen yang sama. Setiap segmen bagi sesuatu alat muzik mempunyai bilangan titik diskrit isyarat akustik yang seragam. Nilai punca min kuasa dua (p.m.k.d) isyarat akustik bagi setiap segmen dikira menggunakan perisian Matlab ${ }^{\circledR}$. Jadual 4 menunjukkan nilai p.m.k.d bagi setiap segmen dan alat muzik. Bagi alat muzik cak lempong dan gambus, dapat diperhatikan bahawa turutan nilai p.m.k.d daripada segmen 1 hingga segmen 5 adalah berbentuk menyusut. Ini adalah disebabkan domain masa kedua-dua isyarat akustik tersebut berbentuk susutan secara eksponen. Maka tenaga isyarat akustik bagi setiap segmen akan menyusut bermula daripada segmen 1 ke segmen 5. Berbeza pula dengan seruling, pola nilai p.m.k.d menunjukkan keadaan yang hampir seragam pada setiap segmen. Ini berpunca daripada penjanaan isyarat itu sendiri yang menunjukkan tenaga bagi setiap isyarat akustik hampir seragam sepanjang seruling tersebut ditiup.

Berdasarkan nilai p.m.k.d tersebut, pekali M-Z-N dikira menggunakan Persamaan 4. Pengiraan ini melibatkan setiap titik diskrit isyarat akustik yang terdapat dalam setiap segmen. Jadual 5 menunjukkan nilai-nilai pekali M-Z-N. Bagi mengkaji kriteria keputusan statistik dengan lebih jelas, nilai-nilai bagi parameter pekali I-kaz dan

JADUAL 4. Nilai p.m.kd bagi setiap segmen berdasarkan alat muzik masing-masing

\begin{tabular}{ccccc}
\hline Isyarat & Parameter & $\begin{array}{c}\text { Cak } \\
\text { lempong }\end{array}$ & Seruling & Gambus \\
& & & \\
\hline \multirow{3}{*}{1} & p.m.k.d segmen 1 & 0.0173 & 0.1518 & 0.0919 \\
& p.m.k.d segmen 2 & 0.0071 & 0.1841 & 0.0153 \\
& p.m.k.d segmen 3 & 0.0029 & 0.2023 & 0.0125 \\
& p.m.k.d segmen 4 & 0.0013 & 0.2161 & 0.0054 \\
& p.m.k.d segmen 5 & 0.000709 & 0.1593 & 0.0018 \\
\hline \multirow{3}{*}{2} & p.m.k.d segmen 1 & 0.0194 & 0.1424 & 0.0806 \\
& p.m.k.d segmen 2 & 0.0077 & 0.2037 & 0.0155 \\
& p.m.k.d segmen 3 & 0.0031 & 0.2110 & 0.0071 \\
& p.m.k.d segmen 4 & 0.0014 & 0.2211 & 0.0036 \\
& p.m.k.d segmen 5 & 0.000698 & 0.1714 & 0.0014 \\
\hline
\end{tabular}

JADUAL 5. Keputusan analisis statistik pekali M-Z-N bagi knot B3

\begin{tabular}{ccc}
\hline Alat Muzik & Isyarat 1 & Isyarat 2 \\
\hline Cak Lempong & $1.4123 \times 10^{-4}$ & $1.7635 \times 10^{-4}$ \\
Seruling & $6.7970 \times 10^{-2}$ & $7.3763 \times 10^{-2}$ \\
Gambus & $3.5000 \times 10^{-3}$ & $2.7000 \times 10^{-3}$ \\
\hline
\end{tabular}

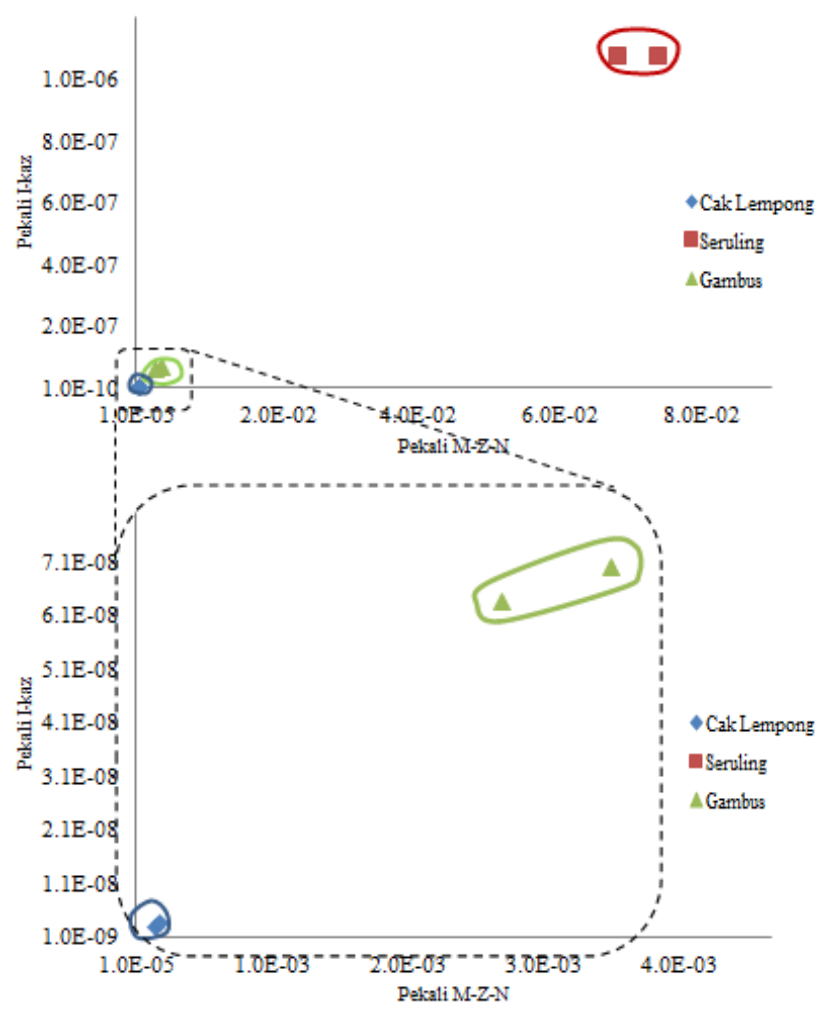

RAJAH 5. Pengelompokan isyarat akustik knot B3 mengikut alat muzik

pekali M-Z-N tersebut diplot.

Rajah 5 menunjukkan graf pengelompokan pekali I-kaz lawan pekali M-Z-N bagi alat muzik cak lempong, seruling dan gambus. Tujuan pengelompokan nilai-nilai parameter statistik dilakukan adalah untuk mengkelaskan dan menentukan perbezaan yang terdapat pada knot yang sama bagi alat muzik yang berbeza. Kaedah ini telah digunakan dengan jayanya oleh penulis untuk menyelesaikan pelbagai masalah kejuruteraan seperti pemantauan mesin, pemantauan enjin blok dan injap kenderaan (Loman et. al 2007; Wahid et. al 2008; Nuawi et. al 2008; Lamin 2009; Nuawi et al. 2013).

Merujuk kepada pengelompokan tersebut, dapat diperhatikan bahawa knot yang sama (B3) bagi alat muzik yang berbeza boleh dikelompokkan pada ciri-ciri statistik masing-masing. Pekali statistik alat seruling mempunyai nilai yang paling tinggi diikuti oleh pekali statistik gambus dan pekali statistik cak lempong. Bentuk domain masa yang pelbagai seperti yang ditunjukkan pada Rajah 3 tidak dapat membezakan isyarat akustik bagi 3 alat tersebut. Justeru itu, dengan menggunakan kaedah pemetaan dan pengelompokan pekali statistik bagi analisis yang terlibat, isyarat akustik bagi knot yang sama dengan alat muzik yang berbeza telah dapat dicirikan pada zon-zon tertentu.

Di samping itu, hasil kajian analisis ini boleh dikembangkan kepada kajian lanjutan sebagai pangkalan data isyarat akustik bagi alat muzik tersebut. Ini adalah kerana alat muzik ini dimainkan oleh pakar-pakar daripada pihak Akademi Seni Budaya Dan Warisan Kebangsaan (ASWARA). Pangkalan data ini boleh digunakan sebagai rujukan bagi pemain-pemain baru yang ingin mempelajari 
cara permainan alat muzik tradisional Melayu tersebut. KESIMPULAN

Dalam kajian ini, satu kaedah pemetaan dan pengelompokan isyarat akustik alat muzik tradisional Melayu telah berjaya dibangunkan. Pembangunan kaedah ini adalah berdasarkan pekali statistik daripada kaedah analisis statistik alternatif iaitu Integrated Kurtosis-based Algorithm for Z-notch filter $\left(\mathrm{I}-\mathrm{kaz}^{\mathrm{TM}}\right)$ dan Mesokurtosis Zonal Nonparametric (M-Z-N). Domain masa isyarat akustik knot B3 bagi alat muzik cak lempong, seruling dan gambus direkod dan bentuk gelombang yang terhasil adalah mengikut kaedah alat muzik tersebut dimainkan. Melalui proses pemetaan dan pengelompokan, keputusan yang diperoleh menunjukkan bahawa isyarat akustik setiap alat muzik yang berbeza boleh dicirikan melalui pekali statistik pada zon-zon tertentu.

\section{PENGHARGAAN}

Penulis merakamkan penghargaan kepada pihak Kementerian Pengajian Tinggi Malaysia di atas pembiayaan penyelidikan ERGS/1/2011/SSI/UKM/02/6 yang diberikan.

\section{RUJUKAN}

Bartholomew, W. T. 1942. Acoustic of Music. New Jersey: Prentice Hall. Inc.

Lamin, F. 2009. Pembangunan Kaedah Pengukuran Isyarat Ultrabunyi Rambatan Struktur untuk Kegunaan Pemantauan Pemesinan. Tesis Sarjana. UKM Bangi.

Loman, M., Nuawi, M. Z., Abdullah, S. \& Jamaludin, N. 2007. Development of Analysis Monitoring using Ultrasonic Signal in Turning Process. Regional Conference on Engineering Mathematics, Mechanics, Manufacturing \& Architecture (EM3ARC).

Nasuruddin, M. G. 1989. Malay Tradisional Music. Kuala Lumpur: Dewan Bahasa dan Pustaka.

Nuawi, M. Z., Bahari, A. R., Abdullah, S., Ihsan A. K. A. \& Ali, M. B. 2012. Mesokurtosis zonal nonparametric signal analysis for dynamic characterisation of metallic material. Jurnal Kejuruteraan 24: 21-27.

Nuawi, M.Z., Bahari,A. R. \& Saad, S. M. 2013. Kajian awal: Pembangunan kaedah pemetaan dan pengelompokan penyebutan perkataan bahasa peranchis bagi penutur di malaysia menggunakan kaedah analisis suara secara statistik. International Conference on KnowledgeInnovation Excellence: Synergy in Language Research and Practice.

Nuawi, M. Z., Lamin, F., Nor, M. J. M., Jamaluddin, N. \& Abdullah, S. 2008. Clustering of Machining Signal for Verifying Machining Parameter. Proceedings of the 1st WSEAS International Conference on Sensors and
Signals.

Nuawi, M. Z., Nor, M. J. M., Jamaluddin, N., Abdullah, S., Lamin, F. \& Nizwan, C. K. E. 2008. Development of integrated kurtosis-based algorithm for Z-filter technique. Journal of Applied Sciences 8 (8): 15411547.

Qu, L. \& He, Z. 1986. Mechanical Diagnostics. Shanghai: Shanghai Science and Technology Press.

Wahid, Z., Nuawi, M. Z., Abdullah, S., Jamaluddin, N., Haris, S. M. \& Zakaria, M. K. 2008. Statistical Analysis on Ultrasonic Signals Measured on Proton Saga Engine Block under Different Rpm: a Comparison. Proceedings of International Conference on Mechanical and Manufacturing Engineering.

Abdul Rahim Bahari

Fakulti Kejuruteraan Mekanikal, Universiti Teknologi MARA Terengganu,

Kampus Bukit Besi, 23200 Bukit Besi Dungun, Terengganu, Malaysia.

Mohd Zaki Nuawi

Jabatan Kejuruteraan Mekanik dan Bahan, Fakulti Kejuruteraan dan Alam Bina, Universiti Kebangsaan Malaysia, 43600 UKM Bangi, Selangor, Malaysia.

Ab Samad Kechot

Pusat Pengajian Bahasa, Kesusasteraan dan Kebudayaan Melayu,

Fakulti Sains Sosial dan Kemanusiaan, Universiti Kebangsaan Malaysia, 43600 UKM Bangi, Selangor, Malaysia.

Firdaus Mohd Hamzah

Unit Pengajian Asas Kejuruteraan

Fakulti Kejuruteraan dan Alam Bina, Universiti Kebangsaan Malaysia, 43600 UKM Bangi, Selangor, Malaysia.

Suziana Mat Saad

Pusat Pengajian Bahasa dan Linguistik, Fakulti Sains Sosial dan Kemanusiaan, Universiti Kebangsaan Malaysia, 43600 UKM Bangi, Selangor, Malaysia.

*Penulis koresponden; emel: abdrahimbahari@gmail.com

Serahan: 25 Nov 2013

Diterima: 4 April 2014 